\title{
Does avian malaria infection affect feather stable isotope signatures?
}

\author{
Elizabeth Yohannes • Vaidas Palinauskas • \\ Gediminas Valkiūnas • Raymond W. Lee • \\ Casimir V. Bolshakov $\cdot$ Staffan Bensch
}

Received: 10 December 2010 / Accepted: 23 May 2011 / Published online: 14 June 2011

\begin{abstract}
It is widely accepted that stable isotope ratios in inert tissues such as feather keratin reflect the dietary isotopic signature at the time of the tissue synthesis. However, some elements such as stable nitrogen isotopes can be affected by individual physiological state and nutritional stress. Using malaria infection experiment protocols, we estimated the possible effect of malaria parasite infections on feather carbon $\left(\delta^{13} \mathrm{C}\right)$ and nitrogen $\left(\delta^{15} \mathrm{~N}\right)$ isotope signatures in juvenile common crossbills Loxia curvirostra. The birds were experimentally infected with Plasmodium relictum (lineage SGS1) and P. ashfordi (GRW2), two widespread parasites of passerines. Experimental birds developed heavy parasitemia of both parasites and maintained high levels throughout the experiment (33 days). We found no
\end{abstract}

Communicated by Scott McWilliams.

E. Yohannes

Stable Isotope Laboratory, Institute for Limnology,

University of Constance, 78464 Constance, Germany

V. Palinauskas $\cdot$ G. Valkiūnas

Nature Research Centre, Akademijos 2, Vilnius 21,

LT 08412, Lithuania

R. W. Lee

School of Biological Sciences, Washington State University,

Pullman, WA 99164-4236, USA

C. V. Bolshakov

Biological Station "Rybachy" of the Zoological Institute,

Russian Academy of Sciences, Rybachy 238535,

Kaliningrad Reg, Russia

S. Bensch $(\bowtie)$

Molecular Ecology and Evolution Lab, Department of Biology,

Lund University, Ecology Building, 22362 Lund, Sweden

e-mail: staffan.bensch@ zooekol.lu.se significant difference between experimental and control birds in both $\delta^{13} \mathrm{C}$ and $\delta^{15} \mathrm{~N}$ values of feathers re-grown. The study shows that even heavy primary infections of malaria parasites do not affect feather $\delta^{13} \mathrm{C}$ and $\delta^{15} \mathrm{~N}$ isotopic signatures. The results of this experiment demonstrate that feather isotope values of wild-caught birds accurately reflect the dietary isotopic sources at the time of tissue synthesis even when the animal's immune system might be challenged due to parasitic infection.

Keywords Plasmodium $\cdot$ Stable isotopes $\cdot$ Infection experiment $\cdot$ Loxia curvirostra

\section{Introduction}

Most birds, particularly migratory species, are exposed to vastly different habitats and hence ecological conditions during their annual cycle. These challenges require adaptations to complex seasonal events and to changing habitat conditions when at or moving between their breeding and wintering grounds (Newton 2008). The impact of seasonally interacting events on the life history has been particularly difficult to demonstrate in small migratory birds because their small sizes makes tracking individuals particularly demanding (reviewed by Webster and Marra 2005). However, information about the habitats and areas used in the annual cycle can be revealed from the ratio of stable isotopes in tissues formed at visited breeding, staging, stopover or wintering sites (Hobson 1999). Inferences of a bird's moulting area from stable isotope analyses rely largely on the use of natural variation in the composition of stable carbon, nitrogen, sulphur and hydrogen isotopes in food webs to provide information on habitat, trophic level, diet and geographical origin (Minagawa and Wada 1984; 
Lajtha and Michener 1994; Hobson 1999; Rubenstein and Hobson 2004). The isotope-ratio signatures of dietary items (food species) in an ecosystem are passed on to herbivorous insects and consumers, such as birds.

In a recent study of great reed warblers (Acrocephalus arundinaceus) sampled at a breeding site in northern Europe, Yohannes et al. (2008) found that malaria-infected birds carried different feather stable isotope signatures compared to non-infected birds for each of the four analysed elements: carbon $\left(\delta^{13} \mathrm{C}\right)$, nitrogen $\left(\delta^{15} \mathrm{~N}\right)$, deuterium $(\delta \mathrm{D})$ and sulphur $\left(\delta^{34} \mathrm{~S}\right)$. This observation suggested that birds moulting in different areas in sub-Saharan Africa were exposed to different rates of malaria infections. This conclusion is inferred from the generally accepted presumption that stable isotope compositions in inert material such as feather keratin reflect the dietary isotopic signals at the time of the tissue synthesis, provided no endogenous stored nutrients are mobilised during tissue formation (Hobson 1999; Kelly 2000).

Elsewhere, there are several studies suggesting that physiological state and nutritional stress of an individual can affect the isotopic values for some elements, such as $\delta^{15} \mathrm{~N}$ (Hobson 2003; Pearson et al. 2003; Voigt and Matt 2004; Kempster et al. 2007). Hence, one could argue that the observed differences in stable isotope signatures between malaria-infected and non-infected great reed warblers (Yohannes et al. 2008) could at least partly result from the malaria infection itself rather than indicating the origin of birds from different geographic areas or habitats. Even if only a partial effect, this would have serious consequences on how feather stable isotope data have been interpreted in many previous studies of birds and other vertebrates. In order to investigate this possibility, we made use of a malaria infection experiment and examined the stable isotope ratios $\left(\delta^{13} \mathrm{C}\right.$ and $\left.\delta^{15} \mathrm{~N}\right)$ in feathers produced during the peak of primary co-infection of the malaria parasites Plasmodium relictum (lineage SGS1) and $P$. ashfordi (GRW2) compared to feathers produced by a non-infected control group. In order to be able to assess whether the nutrients for feather growth came from stored resources or from a daily intake, we used a food source (sunflower seeds) that show a distinctly different $\delta^{15} \mathrm{~N}$ value compared to the natural food source (pine cone seeds) of the experimental species, common crossbills Loxia curvirostra.

Both parasites are widespread in common Palearctic birds and may negatively affect or cause death of hosts during primary co-infections (Palinauskas et al. 2011). If the immune-stress invoked by malaria parasites is affecting the stable isotope composition of feathers, we expect different isotope signatures in feathers from experimental and control birds. Because malaria infections are prevalent in birds in all continents except Antarctica (Valkiūnas 2005), such an effect would have important implications for using stable isotopes in studies of tracking animal movement, exploring seasonally interacting events and migratory connectivity (Webster et al. 2002).

\section{Materials and methods}

Malaria infection experiment

The experiment was carried out at the Biological Station of the Zoological Institute of the Russian Academy of Sciences on the Curonian Spit in the Baltic Sea $\left(55^{\circ} 05^{\prime} \mathrm{N}\right.$, $20^{\circ} 44^{\prime} \mathrm{E}$ ) between June and August 2008. All birds were caught with mist-nets and large 'Rybachy'-type traps. About $30 \mu \mathrm{l}$ of whole blood was taken in heparinised microcapillaries by puncturing the brachial vein and stored in SET-buffer for molecular analysis (Hellgren et al. 2004). A drop of blood was taken from each bird to make two blood films. The smears were air-dried, fixed in absolute methanol, stained with Giemsa and analysed following standard methodology (Valkiūnas et al. 2008).

The details of the infection experiment can be found in Palinauskas et al. (2011). In brief, one garden warbler Sylvia borin with a light natural co-infection of P. (Haemamoeba) relictum (mitochondrial cytochrome $b$ gene lineage SGS1) and $P$. (Novyella) ashfordi (GRW2), as determined by microscopic examination of blood films and PCR-based techniques, was used as a donor of parasites to multiply the strains and then to infect uninfected (recipient) juveniles. Twelve juvenile common crossbills were caught at the study site and used as recipient hosts. All birds were taken from the wild and kept indoors in a vectorfree room under controlled conditions $\left(20 \pm 1{ }^{\circ} \mathrm{C} ; 50-60 \%\right.$ relative humidity; the natural light:dark photoperiod was $17: 7 \mathrm{~h}$ at the beginning and 16:8 $\mathrm{h}$ at the end of the experiment). Before the experiment, all recipient birds were proved to be uninfected with haemosporidian parasites both by microscopic examination of blood films and later by PCR. Sunflower seeds Helianthus annuus and water were offered ad libitum but individual intake rates were not monitored.

Six birds were exposed experimentally to $P$. relictum and $P$. ashfordi infections by inoculation of infected blood in their pectoral muscle, as described by Palinauskas et al. (2008). Six other birds were used as negative controls; they were inoculated with the same amount of non-infected blood from the same host species as the experimental group. The blood for microscopic examination and PCR was taken from all birds as described above once every 3 days for 33 days.

At the start of the experiment, the third outermost wing feathers were removed and stored in paper envelopes. Feathers re-grown during the period were measured to the 
nearest $\mathrm{mm}$ at 12, 24 and 30 days post-inoculation (dpi). At the end of the experiment, the wing feathers re-grown during this experiment ( 5 experimental and 6 control birds) were collected for stable isotope measurement. For the isotopic analysis, we used feather parts from the tip and the middle section ( $35 \mathrm{~mm}$ from the base) of each wing feather. Hence, we analysed two segments (tip and middle) from each feather and two feathers from each bird (one grown in the wild before the experiment and one grown in the captivity after the start of the experiment). At the end of the experiment, we also collected the dietary items, 12 dehulled kernels of sunflower seeds that were also used for stable isotope measurements.

\section{Analyses of feather stable isotopes}

Feather and sunflower kernel sub-samples of ca. $0.35 \mathrm{mg}$ each were weighed in small tin cups to the nearest $0.001 \mathrm{mg}$, using a micro-analytical balance. Samples were then combusted in a Eurovector (Milan, Italy) elemental analyser. The resulting $\mathrm{N}_{2}$ and $\mathrm{CO}_{2}$ gases were separated by gas chromatography and admitted into the inlet of a Micromass (Manchester, UK) Isoprime isotope ratio mass spectrometer (IRMS) for determination of ${ }^{15} \mathrm{~N} /{ }^{14} \mathrm{~N}$ and ${ }^{13} \mathrm{C} /{ }^{12} \mathrm{C}$ ratios. Measurements are reported in $\delta$-notation relative to the Pee Dee Belemnite (PDB) for carbon and atmospheric $\mathrm{N}_{2}$ standard in parts per thousand deviations (\%o). Typical precision of analyses was $\pm 0.5 \%$ ofor $\delta^{15} \mathrm{~N}$ and $\pm 0.2 \%$ ofor $\delta^{13} \mathrm{C}$. A sample of egg albumin was used as a laboratory standard for every 11 unknowns in sequence. Several hundreds of replicate assays of internal laboratory standards (albumen) indicate measurement errors (SD) of $\pm 0.2 \%$ and $\pm 0.5 \%$ o for $\delta^{13} \mathrm{C}$ and $\delta^{15} \mathrm{~N}$, respectively.

\section{Statistical analyses}

We used two-way ANOVAs to investigate the effect of treatment (malaria infected or control birds) and the identity of the birds as we had two measurements (the tip and middle sections of the feathers) from each individual. In all cases, the interaction terms were non-significant $(P>0.1)$ and therefore dropped from the final models. To calculate the statistical power of detecting an effect of malaria infection on the stable isotope profiles, we used the program G*Power 3 (Faul et al. 2007).

\section{Results}

Parasitemia of both $P$. relictum and $P$. ashfordi developed in all the experimentally infected birds. The prepatent period of co-infection was on average 4 days and parasitemia reached the first peak at around $13 \%$ on $9 \mathrm{dpi}$; it maintained

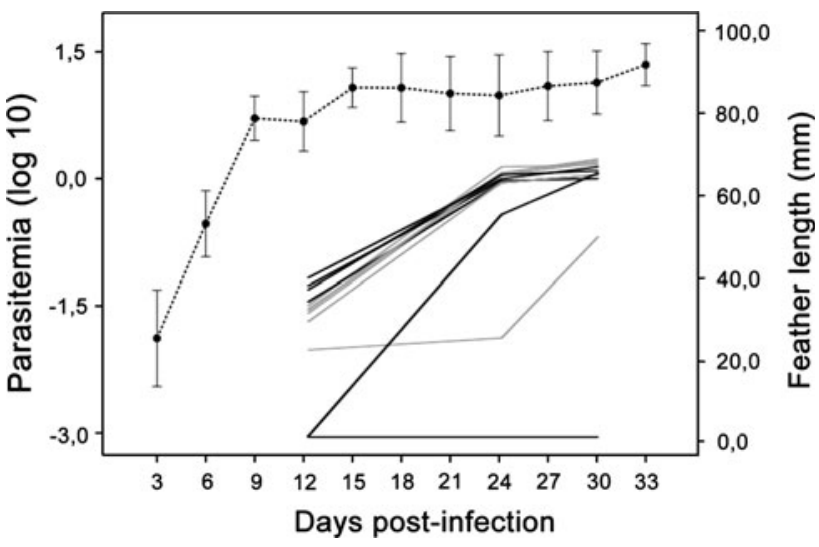

Fig. 1 Dynamics of mean parasitemia (left axis, stippled line) of co-infection with Plasmodium relictum (lineage SGS1) and $P$. ashfordi (GRW2) in experimentally infected common crossbills Loxia curvirostra relative to days post-infection (dpi). Right axis shows length of growing wing feathers for individual birds (black infected, grey controls) measured at 12, 24 and 30 dpi

this high level throughout this experiment (Fig. 1). The tips of the re-growing feathers were visible 3-6 dpi and all birds except one malaria inoculated bird re-grew the plucked wing feather during the 33-day period (Fig. 1). We used the tip and the middle sections of the feathers for isotopic analyses and, according to the results in Fig. 1, the synthesis of these portions of the feathers grown in captivity coincided with the increase of parasitemia (tip) and when the peak of parasitemia had been reached (middle).

The $\delta^{15} \mathrm{~N}( \pm \mathrm{SE})$ in the replacement feathers $(8.19 \pm 0.17)$ were substantially higher than in the wild-grown feathers $(1.74 \pm 0.15)$, with a tendency of the identity of the birds (Fig. 2) to have a significant effect in the model (ANOVA, feather $F_{1,33}=821.9, P<0.001$; individual $F_{11,33}=1.74$, $P=0.071)$. The $\delta^{15} \mathrm{~N}$ values of the replacement feathers matched the isotopic signature of the sunflower seeds $(8.91 \pm 0.58)$. The isotopic signatures of $\delta^{13} \mathrm{C}$ were more similar between wild-grown $(-20.53 \pm 0.11)$ and replacement feathers $(-19.97 \pm 0.12)$ with a highly significant effect of the identity of the birds (Fig. 2) in the model (ANOVA, feather $F_{1,33}=12.4, \quad P=0.001 ;$ individual $\left.F_{11,33}=5.26, P<0.001\right)$. The $\delta^{13} \mathrm{C}$ values of both the wildgrown and the replacement feathers matched the isotopic signature of the sunflower seeds $(-20.66 \pm 0.52)$.

Because the wild-grown feathers of experimental and control birds were grown before the start of the experiment, we did not expect any difference between them. As expected, $\delta^{13} \mathrm{C}$ and $\delta^{15} \mathrm{~N}$ did not differ in the wild-grown feathers (ANOVA, $\delta^{15} \mathrm{~N}$, treatment $F_{1,12}=0.005, P=0.95$; $\delta^{13} \mathrm{C}$, treatment $F_{1,12}=0.011, P=0.92$ ) but for both elements the tip and the middle sections of the feathers were more similar within than between individuals (ANOVA, 
Fig. 2 Wing feather $\delta^{13} \mathrm{C}$ and $\delta^{15} \mathrm{~N}$ values of common crossbills infected with Plasmodium relictum (lineage SGS1) and $P$. ashfordi (GRW2) (b, d) and compared with control (noninfected) birds (a, c). Replacement feathers were grown when birds were held in captivity on a diet of sunflower seeds (stippled lines show the isotopic signatures of the seeds). Sub-sample feathers from the tip and the middle section of each feather were used for analysis
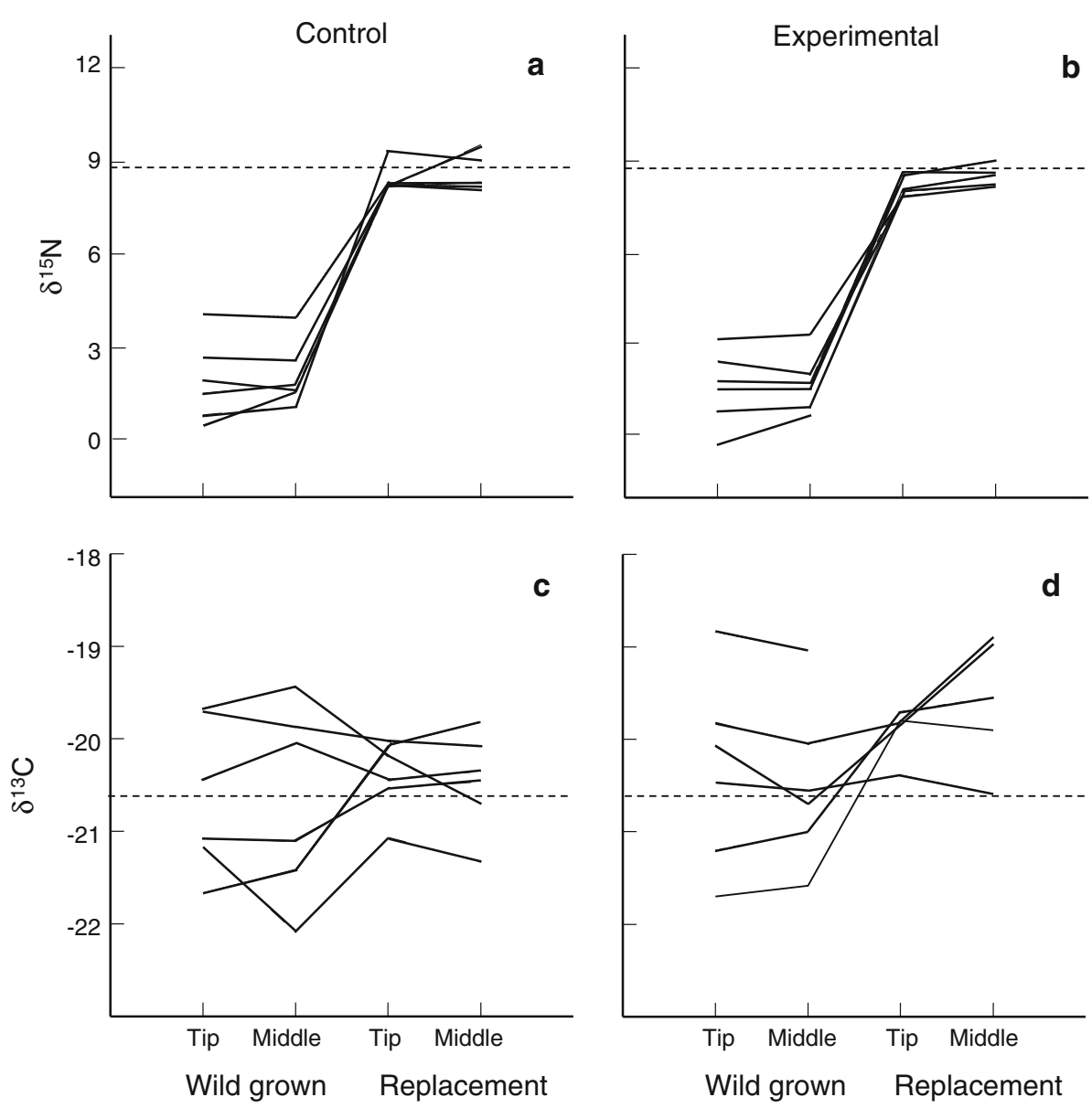

$\delta^{15} \mathrm{~N}$, individual $F_{11,12}=21.7, P<0.001 ; \delta^{13} \mathrm{C}$, individual $\left.F_{11,12}=23.6, P<0.001\right)$.

If malaria infections influence the stable isotope values in growing feathers, we expected to find the $\delta^{13} \mathrm{C}$ and $\delta^{15} \mathrm{~N}$ values in the replacement feathers to differ between the treatments. However, there was no difference between experimental and control birds in the replacement feathers (ANOVA; $\delta^{15} \mathrm{~N}$, treatment $F_{1,12}=0.75, P=0.40 ; \delta^{13} \mathrm{C}$, treatment $F_{1,12}=3.19, P=0.102$ ). Similar to the wildgrown feathers, the tip and the middle sections of the feathers were more similar within than between individuals (ANOVA; $\delta^{15} \mathrm{~N}$, individual $F_{11,12}=2.41, P=0.085 ; \delta^{13} \mathrm{C}$, individual $F_{11,12}=3.98, P=0.017$ ).

In the previous study of great reed warblers (Yohannes et al. 2008), malaria-infected and non-infected birds showed mean differences in $\delta^{13} \mathrm{C}$ of $1.27 \%$ (overall $\mathrm{SD}=3.08$ ) and in $\delta^{15} \mathrm{~N}$ of $0.73 \%$ (overall $\mathrm{SD}=1.67$ ). This corresponds to effect sizes $(d)$ of 0.41 for $\delta^{13} \mathrm{C}$ and 0.44 for $\delta^{15} \mathrm{~N}$. In our present experiment, we had six control and five experimental birds. By setting $\alpha=0.05$ and using the effect sizes from the study by Yohannes et al. (2008), the statistical power of the tests were 0.154 for $\delta^{13} \mathrm{C}$ and 0.165 for $\delta^{15} \mathrm{~N}$. The combined statistical power, i.e. rejecting the null hypothesis for one or both of the elements, can be calculated as one minus the product between the probabilities of not rejecting the null hypothesis for the two elements. Hence, the joint statistical power was 0.293 $[1-(0.846 \times 0.835)]$ assuming the strength of the effect of malaria infection was as in the study of the great reed warbler.

\section{Discussion}

We estimated the possible effect of two widespread malaria infections on feather isotope signatures and detected no significant difference between the experimental and control birds in $\delta^{13} \mathrm{C}$ and $\delta^{15} \mathrm{~N}$ of replacement feathers. Importantly, all experimental infections were acute primary infections, which are known to be particularly harmful to birds (Garnham 1966; Atkinson et al. 2001; Zehtindjiev et al. 2008). Hence, our study suggests that avian malarial infections do not impose any substantial influence on feather $\delta^{13} \mathrm{C}$ and $\delta^{15} \mathrm{~N}$ isotopic signatures. Because of the small sample size $(n=11)$, we have relatively low statistical power (0.30) of rejecting the null hypothesis if we assume the same effect size as in the study of Yohannes et al. (2008). However, the intensity of infections in wild-caught 
birds are typically much lower than in our experiment (Valkiūnas 2005). Hence, one can argue that if the differences in $\delta^{13} \mathrm{C}$ and $\delta^{15} \mathrm{~N}$ values between feathers of the malaria-infected and non-infected great reed warblers were caused by the malaria infections, our experiment involving heavily infected birds should have allowed for detecting an effect, if malaria infections would have shifted the isotopic values in a similar way in the crossbills.

In both experimental and control groups replaced feather $\delta^{13} \mathrm{C}$ and $\delta^{15} \mathrm{~N}$ were similar to the isotope values of the sunflower seeds on which the birds were fed during the experiment. This implies that interpretation of feather isotope data of free-ranging birds can be used as an accurate signal of the dietary isotopic values at the time of the tissue synthesis even when the animal's immune status might be challenged due to infection or parasite load. We previously found that malaria-infected great reed warblers exhibited different feather stable isotope signatures compared to noninfected birds (Yohannes et al. 2008). The present experiment supports the interpretation that the different isotopic signatures are caused by the birds moulting feathers in separate geographic regions associated with different rates of malaria transmission due to climatic, habitat or as yet unknown processes.

Parasitic infections induce additional demands on host resources, through direct competition for energy or resources (Coop and Holmes 1996; Sorensen and Minchella 1998) or by altering the functional activity of the host's immune system (Moret and Schmid-Hempel 2000). Parasites have also been shown to modify the feeding patterns of their hosts (Moore 1995). Hosts may attempt to compensate for the increased nutritional demands caused by parasites by increasing their foraging effort (Thompson 1990). Because we did not monitor food and water intake rates by the individual birds, we were not able to investigate this aspect in more detail. Previously, using the birds from the same experiment (Palinauskas et al. 2011), we showed that the infected birds kept their body mass at the same level as the control birds until $27 \mathrm{dpi}$ whereafter they showed a significantly lower body mass. This observation suggests that the infected birds were able to cover the higher energy demands caused by the malaria infections throughout most of the experimental period by increasing their food intake, without using stored energy or proteins that would lead to weight loss and more likely a shift in isotopic values. Hosts may also attempt to compensate for the increased nutritional demands caused by parasites by altering their food sources (Miura et al. 2006). The birds in the present experiment were constrained to the restricted food provided and therefore could not alter their food sources. However, if birds in the wild change their dietary preferences relative to infection status, feather stable isotope signatures may be affected in a different pattern than observed in the present experiment.
Because parasites feed on host tissues, they can become significantly enriched in $\delta^{15} \mathrm{~N}$ relative to the host (Boag et al. 1998; Doucett et al. 1999; Power and Klein 2004; O'Grady and Dearing 2006). Depending on the infection intensity, blood $\delta^{15} \mathrm{~N}$ values could be significantly higher in infected than in uninfected birds, which could be caused by the higher $\delta^{15} \mathrm{~N}$ ratio in parasites. In such cases, the parasitic load in the blood sample used to measure the $\delta^{15} \mathrm{~N}$ ratio should be of a higher percentage. However, this question remains to be tested empirically.

In our experiment, the birds were held on a diet that had a different $\delta^{15} \mathrm{~N}$ signature compared to feathers grown in the wild. This let us see a shift in feather $\delta^{15} \mathrm{~N}$ and to trace whether birds mobilise stored resources to compensate demands induced by the infection. However, replacement feathers of both experimental and control birds showed $\delta^{15} \mathrm{~N}$ values similar to diet, indicating that the experimental diet has been the major nutrient source for feather growth. It is possible that our small sample sizes limited our ability to detect minor differences between infected and uninfected birds, in general. We propose that future studies should address whether food sources of host birds are altered by malaria parasite infection, and whether the isotope ratios of infected tissues (blood and feather) differ from uninfected tissues. Also, different species of avian malaria parasites may exploit and damage different tissues of the host (Valkiūnas 2005) which may affect the isotopic signatures both of the parasites and the host. Hence, further details about host behaviour and parasite pathology will be essential for understanding energy and resource allocation of hosts infected by parasites.

Acknowledgments The present study was supported by the Swedish Research Council (621-2007-5193), the Lithuanian State Science and Studies Foundation, NSF Grant DBI-011620 and Max-Planck Society. The experiments described herein comply with the current laws of Sweden, Russia and Lithuania. The authors are grateful to the staff of the Biological Station "Rybachy" of the Zoological Institute of the Russian Academy of Sciences for assistance in the field. We thank Scott McWilliams, Petr Prochazka and an anonymous reviewer for valuable comments on the manuscript.

\section{References}

Atkinson CT, Dusek RJ, Lease JK (2001) Serological responses and immunity to superinfection with avian malaria in experimentallyinfected Hawaii Amakihi. J Wildl Dis 37:20-27

Boag BR, Neilson D, Robinson CM, Csrimgeou R, Handley LL (1998) Wild rabbit host and some parasites show trophic level relationships for a first report. Isot Environ Health Stud 34:81-85

Coop RL, Holmes PH (1996) Nutrition and parasite interaction. Int J Parasitol 26:951-962

Doucett RR, Giberson DJ, Power G (1999) Parasitic association of Nanocladius (Diptera: Chironomidae) and Pteronarcys biloba (Plecoptera: Pteronarcyidae): insights from stable-isotope analysis. J North Am Benthol Soc 18:514-523 
Faul F, Erdfelder E, Lang A-G, Buchner A (2007) G*Power 3: a flexible statistical power analysis program for social, behavioral, and biometrical sciences. Behav Res Meth 39:175-191

Garnham PCC (1966) Malaria parasites and other Haemosporidia. Blackwell, Oxford

Hellgren O, Waldenström J, Bensch S (2004) A new PCR assay for simultaneous studies of Leucocytozoon, Plasmodium, and Haemoproteus from avian blood. J Parasitol 90:797-802

Hobson KA (1999) Tracing origins and migration of wildlife using stable isotopes: a review. Oecologia 120:314-326

Hobson KA (2003) Making migratory connections with stable isotopes. In: Berthold P, Gwinner E, Sonnenschein E (eds) Avian migration. Springer, Berlin, pp 379-391

Kelly JF (2000) Stable isotopes of carbon and nitrogen in the study of avian and mammalian trophic ecology. Can J Zool 78:1-27

Kempster B, Zanette L, Longstaffe FJ, MacDougal-Shackleton SA, Wingfield JC, Clinchy M (2007) Do stable isotopes reflect nutritional stress? results from a laboratory experiment on song sparrows. Oecologia 151:365-371

Lajtha K, Michener RH (1994) Stable isotopes in ecology and environmental science. Blackwell, Oxford

Minagawa M, Wada E (1984) Stepwise enrichment of ${ }^{15} \mathrm{~N}$ along food chains: further evidence and the relation between ${ }^{15} \mathrm{~N}$ and animal age. Geochim Cosmochim Acta 48:1135-1140

Miura O, Kuris AM, Torchin ME, Hechinger RF, Chiba S (2006) Parasites alter host phenotype and may create a new ecological niche for snail hosts. Proc R Soc Lond B 273:1323-1328

Moore J (1995) The behavior of parasitized animals. Bioscience 45:89-96

Moret Y, Schmid-Hempel P (2000) Survival for immunity: the price of immune system activation for bumblebee workers. Science 290:1166-1168

Newton I (2008) The migration ecology of birds. Academic, London

O'Grady SP, Dearing MD (2006) Isotopic insight into host- endosymbiont relationships in liolaemid lizards. Oecologia 150:355-361

Palinauskas V, Valkiūnas G, Bolshakov CV, Bensch S (2008) Plasmodium relictum (lineage P-SGS1): effects on experimentally infected passerine birds. Exp Parasitol 120:372-380

Palinauskas V, Valkiūnas G, Bolshakov CV, Bensch S (2011) Plasmodium relictum (lineage SGS1) and Plasmodium ashfordi (lineage GRW2): the effects of the co-infections on experimentally infected passerine birds. Exp Parasitol 127:527-533
Pearson SF, Levey DJ, Greenberg CH, Martínez del Rio C (2003) Effects of elemental composition on the incorporation of dietary nitrogen and carbon isotopic signatures in an omnivorous songbird. Oecologia 135:516-523

Power M, Klein GM (2004) Fish host-cestode parasite stable isotope enrichment patterns in marine, estuarine and freshwater fishes from northern Canada. Isot Environ Health S 40:257-266

Rubenstein DR, Hobson KA (2004) From birds to butterflies: animal movement patterns and stable isotopes. Trends Ecol Evol $19: 256-263$

Sorensen RE, Minchella DJ (1998) Parasite influences on host life history: Echinostoma revolutum parasitism of Lymnaea elodes snails. Oecologia 115:188-195

Thompson SN (1990) Physiological alterations during parasitism and their effects on host behaviour. In: Barnard J, Behnke JM (eds) Parasitism and host behavior. Taylor and Francis, London, pp 64-94

Valkiūnas G (2005) Avian malaria parasites and other haemosporidia. CRC Press, Boca Raton

Valkiūnas G, Iezhova TA, Krizanauskiene A, Palinauskas V, Sehgal RNM, Bensch S (2008) A comparative analysis of microscopy and PCR-based detection methods for blood parasites. J Parasitol 94:1395-1401

Voigt CC, Matt F (2004) Nitrogen stress causes unpredictable enrichments of ${ }^{15} \mathrm{~N}$ in two bat species. J Exp Biol 207:1741-1748

Webster MS, Marra PP (2005) The importance of understanding migratory connectivity and seasonal interactions. In: Greenberg R, Marra PP (eds) Birds of Two Worlds: the ecology and evolution of migration. John Hopkins University Press, Baltimore, pp 199-209

Webster MS, Marra PP, Haig SM, Bensch S, Holmes RT (2002) Links between worlds; unraveling migratory connectivity. Trends Ecol Evol 17:76-83

Yohannes E, Hansson B, Lee RW, Waldenström J, Westerdahl H, Åkesson M, Hasselquist D, Bensch S (2008) Isotope signatures in winter moulted feathers predict malaria prevalence in a breeding avian host. Oecologia 158:299-306

Zehtindjiev P, Ilieva M, Westerdahl H, Hansson B, Valkiūnas G, Bensch S (2008) Dynamics of parasitemia of malaria parasites in a naturally and experimentally infected migratory songbird, the great reed warbler Acrocephalus arundinaceus. Exp Parasitol 119:99-110 